\title{
Essential Oil and Anatomical Study of Flowers Solidago caucasica Kem.-Nath.
}

\author{
Victoria Vladimirovna Fedotova, Dmitry Alexeevich Konovalov*
}

\section{Victoria Vladimirovna Fedotova, Dmitry Alexeevich Konovalov*}

\section{Department of Pharmacognosy} and Botany, Pyatigorsk Medical and Pharmaceutical Institute, A Branch of Volgograd State Medical University, Ministry of Health of Russian Federation, Pyatigorsk, 357532, Kalinina 11, RUSSIA.

\section{Correspondence}

\section{Dmitry Alexeevich Konovalov}

Pyatigorsk Medical and Pharmaceutical Institute, Pyatigorsk, 357532, Kalinina 11, RUSSIA.

Phone no : +7 89283519349

E-mail: d.a.konovalov@pmedpharm.ru

\section{History}

- Submission Date: 07-07-2018,

- Review completed: 26-08-2018,

- Accepted Date: 14-09-2018

\section{DOI : 10.5530/pj.2018.6s.12}

\section{Article Available online}

http://www.phcogj.com/v10/i6s

\section{Copyright}

(C) 2018 Phcog.Net. This is an openaccess article distributed under the terms of the Creative Commons Attribution 4.0 International license.

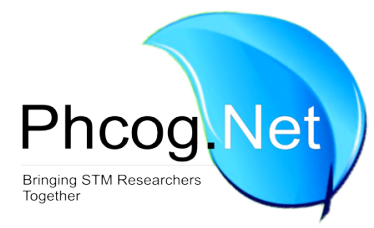

\begin{abstract}
Introduction: Plant Solidago caucasica Kem.-Nath. (Asteraceae) is studied by us for the first time. We have established its diuretic and antimicrobial action. The study of essential oil and the anatomical structure of $S$. caucasica flowers is presented for the first time in this article. Materials and Methods: S. caucasica flowers were collected at the beginning of flowering in the botanical garden of the Pyatigorsk Medical and Pharmaceutical Institute. Essential oil was obtained by hydro distillation. The component composition of the essential oil was studied by liquid chromatography-mass spectrometry. Results: The main components of essential oil and microscopic diagnostic signs of S. caucasica flowers were established. Solidago caucasica flowers contain $0.57 \%$ essential oil. It contains humulene epoxide $\mathrm{H}(-)$-spathulenol, $\beta$-linalool, $\alpha$-terpinol, trans-geraniol, carvacrol and others. Numerous pappus hairs meet in the microscopy of the flower. Ligulate florets are characterized by round chromoplasts, covering trichomes multicellular. Epidermal cells of the tubular florets have polygonal chromoplasts, trichomes, consisting of several cells fused with each other, covering trichomes with a thick wall and a thin cavity inside. On the epidermis of the involucre there are stomata of anomocytic type, glandular trichomes, trichomes cone-shaped, trichomes wide and essential oil glands. Conclusion: The obtained standards will provide referential information for correct identification, purity, standardization and preparation of monograph of S. caucasica.

Key words: Chromoplasts, Humulene epoxide, Pathulenol, Solidago caucasica Kem.-Nath.,
\end{abstract} Trichomes.

\section{INTRODUCTION}

We first explored Solidago caucasica Kem.-Nath (Goldenrod caucasian). Earlier in the grass of this plant, we found flavonoids (rutin, vicenin, hesperidin), coumarins (umbelliferone, esculetin, dihydrocoumarin), phenol carboxylic acids (gallic, chicory, chlorogenic and caffeic acid), ${ }^{1}$ tannins, organic acids (citric, malic and succinic acid), triterpene glycosides (oleanolic acid), ${ }^{2}$ carbohydrates, ${ }^{3}$ fatty acids, polyhydric alcohols and their derivatives, amino acids. In the rhizomes with roots of S. caucasica were found phenolic carboxylic acids, tannins, polyacetylene compounds, triterpene glycosides, carbohydrates and amino acids. ${ }^{2}$

We established the diuretic and antimicrobial activity of the herb extract of S. caucasica. ${ }^{2}$ However, according to literature data, flowers of another species, $S$. virgaurea L., also have a diverse chemical composition (flavonoids, phenol carboxylic acids, coumarins, essential oils, triterpenoids) and are used in folk medicine as a diuretic and wound healing agent. ${ }^{4}$ In connection with the above, a more detailed study of $S$. caucasica flowers is necessary.

\section{MATERIALS AND METHODS}

The object of this study was the flowers of S. caucasica, collected during the beginning of flowering in August
2015 in the botanical garden of the Pyatigorsk Medical and Pharmaceutical Institute. ${ }^{5}$ (Figure 1).

The essential oil was obtained by hydrodistillation in a Clevenger apparatus, hexane was used as the trap. The studies were carried out on chromatography-mass spectrograph an «Agilent Technolog» 6850/5973, HP-5MS capillary quartz column (30.0 m long, $250 \mu \mathrm{m}$ in diameter). Analysis conditions: helium carrier gas, carrier gas flow rate $1.2 \mathrm{ml} / \mathrm{min}$, column temperature is programmed from $60^{\circ} \mathrm{C}$ to $280^{\circ} \mathrm{C}$ at a rate of 20 degrees per minute, sample volume $1 \mu$, route of administration: without dividing the flow. Mass spectrometric detection conditions: the analysis was performed in a full ion current scan (SCAN); ion source temperature $230^{\circ} \mathrm{C}$, analyzer temperature $150^{\circ} \mathrm{C}$, mass range $\mathrm{m} / \mathrm{z}$ 41-650 u.; voltage: the result of the automatic tuning for perfluorobutylamine in the ATUNE $+100 \mathrm{kV}$ mode. The identification of the substances was carried out by comparing the mass spectra with standard library spectra WILEY, NIST08 and NIST02.

The anatomical structure of $S$. caucasica flowers is considered in accordance with the requirements of 


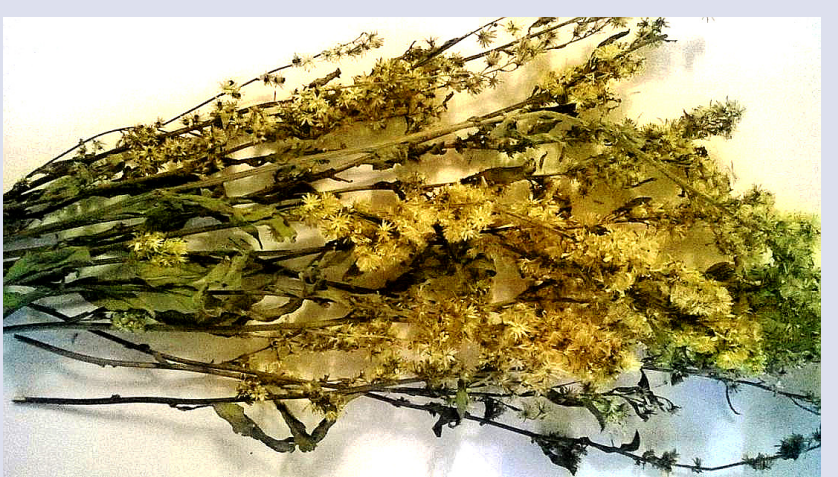

Figure 1: Solidago caucasica Kem.-Nath.

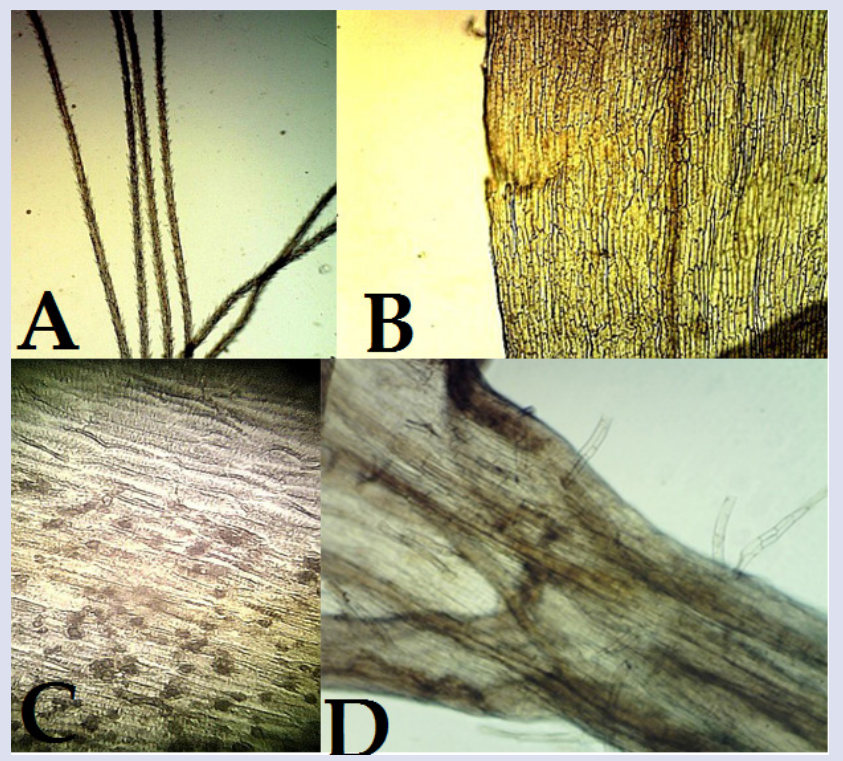

Figure 2: Pappus hairs (A) (160X) and ligulate florets of S. caucasica: $B$ - epidermis (128x); C - chromoplasts and cuticle (160X); D - covering trichomes (128x).

the State Pharmacopoeia XIII. ${ }^{6}$ The material was fixed in the system ethyl alcohol-glycerol-water in the ratio 1: 1: 1 .

Micro preparations were studied on a microscope "Biomed", lenses $\times 4$, $\times 10$, eyepiece $16 \times$. Microphotographs were made on a digital camera «3.0mp cmos microscope eyepiece new».

\section{RESULTS}

The essential oil content averaged $0.57 \%$. Solidago caucasica essential oil identified $\beta$-linalool, cis-pinocarveol, $\alpha$-terpinol, trans-geraniol, carvacrol, decanoic acid, cis-lanceol, isoaromadendrene epoxide, (-)-spathulenol, humulene epoxide, aromadendrene oxide-(2), cis-z- $\alpha$-bisabolene epoxide. The main components of the essential oil are humulene epoxide and (-)-spathulenol.

Anatomical study of flowers. There are numerous pappus hairs (bristly structures) consisting of the hairs of different length which have grown together with the free pointed ends (Figure 2-A). The cells of the epidermis

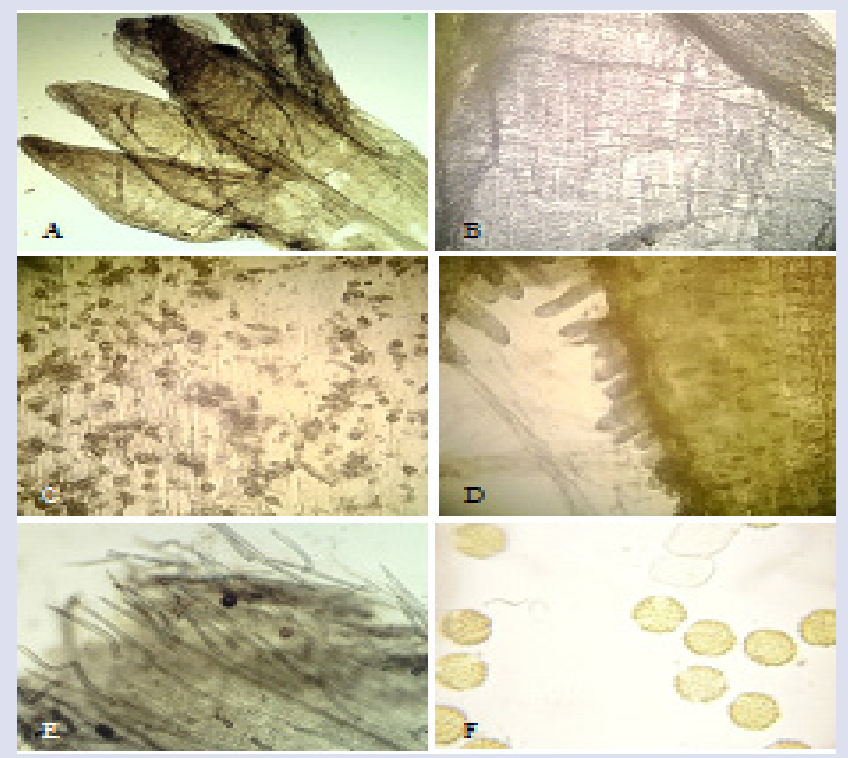

Figure 3: Tubular florets of S. caucasica: A - general form (64x); B cuticle (160x); C - chromoplasts (160x); D - trichomes, consisting of several cells fused with each other (128x); E - covering trichomes (128x); F - pollen grains (640x).

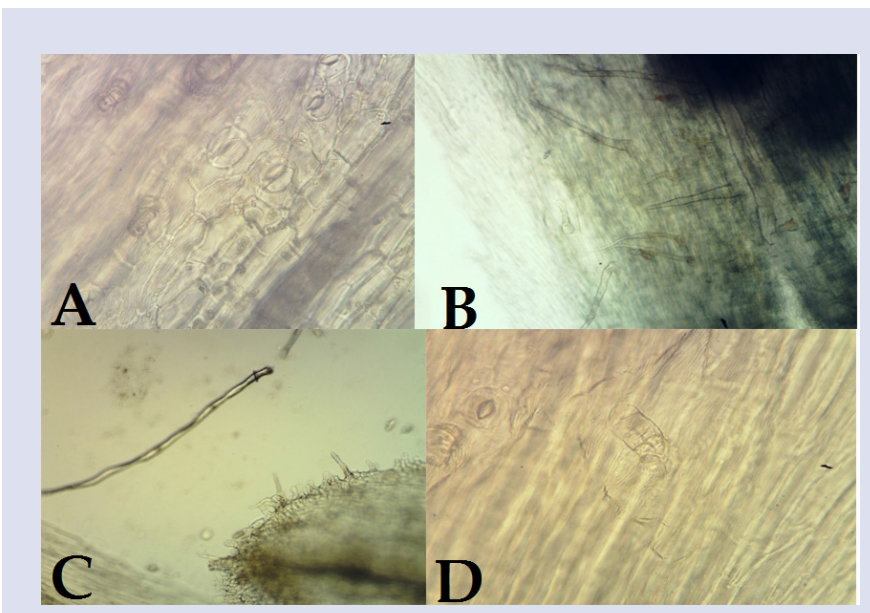

Figure 4: Involucre of S. caucasica: A - stomata and glandular trichomes (640X); B - Covering trichomes on the surface (160X); C -trichomes on the edge (160x); D - essential oil gland (640x).

of ligulate florets are rectangular, the cell walls are straight or slightly sinuous, the thickening is uniform, the chromoplasts are rounded (Figure 2-B). The cuticle transversely wrinkled, the stomata absent (Figure 2-C). On the ligulate florets there are covering trichomes multicellular, the walls of the hairs are thin, the surface is smooth (Figure 2-D). The epidermis of tubular florets consists of cells of rectangular form (Figure 3-A), the cell walls are straight or slightly sinuous, a thickening is uniform and the chromoplasts are polygonal (Figure 3-C). The cuticle transversely wrinkled, the stomata absent (Figure 3-B). At the edge of the flower are trichomes, consisting of several cells fused with each other (Figure 3-D). 
There are numerous covering trichomes with a thick wall and a thin cavity inside. Some covering trichomes are two-pointed (Figure 3-E). The pollen grains is rounded, surface prickly, three-barbed (Figure 3-F). Cells of the epidermis of the involucre are also rectangular form, the cell walls are straight or slightly sinuous, the cuticle transversely wrinkled. There are numerous stomata. The stomata belongs to anomocytic type. Cells of the stomata are lenticular or spherical. The stomata are located on the same level as the epidermis. Glandular trichomes have a unicellular stem with a single-, two-celled head (Figure 4-A).

On the edge of the flower are papillate outgrowths. On the surface there are covering trichomes - simple expanding cone-shaped hairs (Figure 4-B). At the edge of the involucre are wide trichomes (Figure 4-C). Essential oil glands such as Asteraceae (Figure 4-D).

\section{DISCUSSION}

Thus, the main components of the essential oil of S. caucasica flowers are humulene epoxide and (-) - spathulenol.

The main anatomical signs of $S$. caucasica flowers are: essential oil glands on the epidermis of the involucre;

Covering trichomes multicellular on the ligulate florets; trichomes of tubular florets, consisting of several cells fused with each other; the pollen grains is rounded, surface prickly, three-barbed; trichomes of involucre; numerous pappus hairs.

\section{CONCLUSION}

The present study deals with the pharmacognostic evaluation of S. caucasica. The morphological and microscopical characters of plant and pow- der were studied. The present study will provide useful information for correct identification, purity and standardization of plant. In addition the results of the present study could be useful for preparation of a monograph of the S. caucasica.

\section{ACKNOWLEDGEMENT}

The authors are grateful to the head of Pyatigorsk medical and pharmaceutical Institute V. L. Adgienko.

\section{CONFLICT OF INTEREST}

The authors have no conflict of interest to declare.

\section{REFERENCES}

1. Fedotova W, Chelombit'ko VA. Study of phenolic compounds Solidago caucasica Kem.-Nath. Scientific statements BSU. Series Medicine Pharmacy. 2012; 10(129);18:175-7.

2. Fedotova VV. Pharmacognosic research Solidago caucasica Kem.-Nath. Ph. D. Thesis, Pyatigorsk Medical and Pharmaceutical Institute, a Branch of Volgograd State Medical University, Pyatigorsk, Russian Federation. 2014.

3. Fedotova VV, Chelombit'ko VA, Malikova MK. Carbohydrates from Solidago caucasica herb. Chemistry of Natural Compounds. 2013;49(4):726-7.

4. Sokolov PD. Editor. Plant resources of the USSR: Flowering plants, their chemical composition, the use. The family Asteraceae (Compositae). St. Petersburg Science. 1993.

5. Adzhienko VL, Voronkov AV, Grigorian SS, Vdovenko-Martynova NN, Serebryanaya FK, Jitar BN, et al. Botanical Garden - historical review and prospects of development. Pharmacy and Pharmacology. 2013;1:24-8.

6. State Pharmacopoeia of the Russian Federation. $13^{\text {th }}$ ed.; 2. Ministry of Health RF. 2015.

\section{ABOUT AUTHORS}

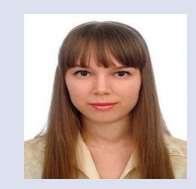

Fedotova Victoria Vladimirovna, Candidate of Pharmaceutical Sciences, Lecturer, Department of Pharmacognosy and Botany, Pyatigorsk MedVolgograd State Medical University, Ministry of Health of Russian Federation. Area of expertise: Pharmacognosy, Phytochemistry, Study of Solidago caucasica, Biosynthesis of silver nanoparticles.

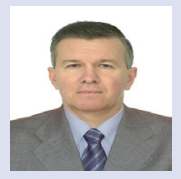
lactones, Polyacetylene compounds. ical and Pharmaceutical Institute, a Branch of

\section{SUMMARY}

- Solidago caucasica flowers contain $0.57 \%$ essential oil. It contains humulene epoxide and (-)-spathulenol, $\beta$-linalool, $\alpha$-terpinol, trans-geraniol, carvacrol and others.

- There are numerous pappus hairs in the microscopy of the flower.

- Ligulate florets are characterized by round-shaped chromoplasts, trichomes multicellular.

- Epidermal cells of a tubular florets with polygonal chromoplasts, there are trichomes, consisting of several cells fused with each other, covering trichomes with a thick wall and a thin cavity inside.

- On the epidermis of the involucre there are stomata of anomocyte type, glandular trichomes, covering trichomes, papillate outgrowths, essential oil gland.

Konovalov Dmitry Alexeevich, Doctor of Pharmaceutical Sciences, Professor, Head of the Department of Pharmacognosy and Botany, Pyatigorsk Medical and Pharmaceutical Institute - Branch of Volgograd State Medical University of the Ministry of Health of Russia. Area of expertise: Phytochemistry, Pharmacognosy, Sesquiterpenic

Cite this article: Fedotova WV, Konovalov DA. Essential Oil and Anatomical Study of Flowers Solidago caucasica Kem.-Nath. Pharmacog J. 2018;10(6)Suppl:s63-s65. 